\title{
Review
}

\section{Role of necroptosis in the pathogenesis of solid organ injury}

\author{
H Zhao ${ }^{1}$, T Jaffer ${ }^{1}$, S Eguchi ${ }^{1}$, Z Wang ${ }^{1}$, A Linkermann ${ }^{2}$ and D Ma ${ }^{\star, 1}$
}

Necroptosis is a type of regulated cell death dependent on the activity of receptor-interacting serine/threonine-protein (RIP) kinases. However, unlike apoptosis, it is caspase independent. Increasing evidence has implicated necroptosis in the pathogenesis of disease, including ischemic injury, neurodegeneration, viral infection and many others. Key players of the necroptosis signalling pathway are now widely recognized as therapeutic targets. Necrostatins may be developed as potent inhibitors of necroptosis, targeting the activity of RIPK1. Necrostatin-1, the first generation of necrostatins, has been shown to confer potent protective effects in different animal models. This review will summarize novel insights into the involvement of necroptosis in specific injury of different organs, and the therapeutic platform that it provides for treatment.

Cell Death and Disease (2015) 6, e1975; doi:10.1038/cddis.2015.316; published online 19 November 2015

\section{Facts}

- Necroptosis is a type of regulated cell death dependent on the activity of receptor-interacting serine/threonine-protein (RIP) kinases

- Necroptosis induces inflammation through the release of Danger-associated molecular patterns (DAMPs), such as HMGB-1.

- Necroptosis is closely associated with acute injury in brain, heart, lung, kidney, liver, intestine and pancreas.

\section{Open Questions}

- What is the exact molecular mechanism of necroptosis in solid organ injury?

- How is necroptosis related to diagnosis and prognosis of the solid organ injury?

- Which therapeutic strategy would be the most effective against necroptosis-associated solid organ injury in clinical settings?

Apoptosis and necrosis are two pathologically relevant types of cell death. Apoptosis is programmed cell death controlled tightly during development and in physiological cellular turnover; necrosis, which also occurs in trauma, was thought to occur predominantly in an uncontrolled manner. ${ }^{1}$ Necroptosis involves the loss of membrane integrity, release of damage-associated molecular pattern molecules (DAMPs) and is therefore closely associated with inflammatory response. $^{2}$ It involves the activation of specific death mediators such as receptor-interacting protein (RIP) kinases and mixed-lineage kinase domain-like protein (MLKL). ${ }^{3,4}$ Recent studies implicate that necroptosis is of central relevance in different disease states, such as myocardial infarction, ${ }^{5}$ stroke ${ }^{6}$ and organ graft ischemia-reperfusion injury (IRI). ${ }^{7-9}$ This review will summarize new insights into the molecular mechanisms of necroptosis in different pathological conditions and provide an overview of the currently available therapeutic approaches, which target necroptosis in organ injury.

\section{Molecular Mechanism of Necroptosis}

The molecular pathway of tumor necrosis factor alpha (TNF- $a$ )induced necroptosis is the mostly intensively investigated (Figure 1). TNF- $a$-induced necroptosis involves two members of the receptor-interacting protein (RIP) family of kinases - RIPK1 and RIPK3., ${ }^{3,10}$ Tumor necrosis factor- $a$ (TNF- $a$ ) can bind to one of two receptors, TNFR1 or TNFR2. TNFR activation can cause the activation of NF- $k B$ which leads to the induction of proinflammatory cytokines. ${ }^{11}$ However, the activation of TNFR1 may turn into a death signal, which recruits several proteins. ${ }^{12}$ Upon TNF stimulation, TNFR1 complex $\mathrm{I}$ is formed at the plasma membrane, containing cellular inhibitor of apoptosis protein 1 (ClAP-1) and transforming growth factor- $\beta$-activated kinase 1 (TAK1). ${ }^{13}$

\footnotetext{
${ }^{1}$ Anaesthetics, Pain Medicine and Intensive Care, Department of Surgery and Cancer, Faculty of Medicine, Imperial College London, Chelsea and Westminster Hospital, London, UK and ${ }^{2}$ Division of Nephrology and Hypertension, Christian-Albrechts-University, Kiel, Germany

${ }^{*}$ Corresponding author: D Ma, Anaesthetics, Pain Medicine and Intensive Care, Department of Surgery and Cancer, Faculty of Medicine, Imperial College London, Chelsea and Westminster Hospital, 369 Fulham Road, London SW10 9NH, UK. Tel: +44 0203315 8495; Fax: +44 0203315 5109; E-mail: d.ma@ imperial.ac.uk

Abbreviations: TNF, tumor necrosis factor; TRADD, TNFRSF1A-associated via death domain; TRAF, TNF receptor associated factors; cIAPs, cellular inhibitor of apoptosis protein; CYLD, deubiquitinase cylindromatosis; MLKL, mediator mixed-lineage kinase domain like; RIP, receptor-interacting protein kinase; Drp1, dynaminrelated protein 1; TAK1, transforming growth factor- $\beta$-activated kinase 1; HMGB-1, high-mobility group protein B1; HSP, heat shock protein; DAMP, damage-associated molecular patterns; RAGE, advanced glycation end products; TLR, Toll-like receptors; AKI, acute kidney injury

Received 09.7.15; revised 16.9.15; accepted 18.9.15; Edited by E Baehrecke
} 


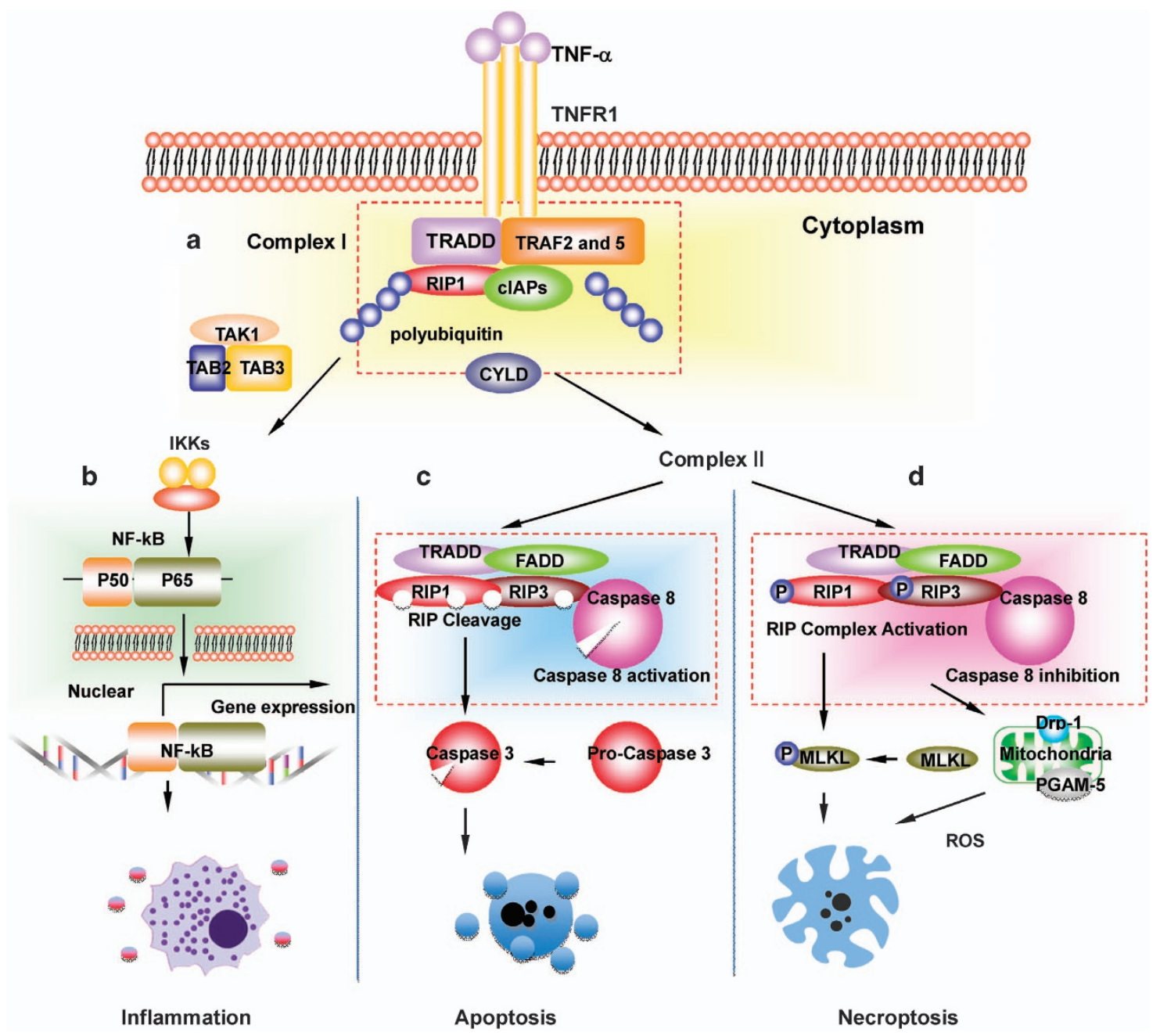

Figure 1 Signalling pathways after stimulation of the TNFR1. TNF- $\alpha$ is widely released during inflammatory conditions. (a) Upon binding to TNF receptor 1 , TNF receptor 1 recruit TRADD, TRAF2 and 5, RIP-1, cIAPs and other molecules to form complex I. (b) Upon polyubiquitinated RIP-1, TNFR1-signalling activates NF-kB, leading to expression of proinflammatory cytokines. The deubiquitination of RIPK1 by CYLD leads to the formation of complex II. (c) Caspase-8 activation in complex II prevents necroptosis through preventing activation RIP, and suppresses the induction of necroptosis. (d) Inactivation of Caspase-8 in complex II leads to the phosphorylation and activation of RIPK1, RIPK3 and MLKL during the assembly of the necrosome. RIPK3 activates PGAM5 and Drp1 to induce reactive oxygen species (ROS) production in the mitochondria and mediate plasma membrane rupture. Abbreviation: TNF, tumor necrosis factor; TRADD, TNFRSF1A-associated via death domain; TRAF, TNF receptor associated factors; cIAPs, cellular inhibitor of apoptosis protein; CYLD, deubiquitinase cylindromatosis; MLKL, mediator mixed-lineage kinase domain like; RIP, receptor-interacting protein kinase; PGAM5, phosphoglycerate mutase 5; Drp1, dynamin-related protein 1

The transition from TNFR1 complex I to the cytosolic deathinducing TNFR1 complex II requires the activity of cylindromatosis (CYLD), a deubiquitylating enzyme. ${ }^{14}$ More recent data ${ }^{15,16}$ suggest that CYLD likely regulates activation of RIPK1 in Complex II, rather than transition from Complex I to Complex II. Within TNFR1 complex II, the apoptotic machinery FADD, c-FLIP and caspase-8 suppresses the induction of necroptosis. Caspase-8 inactivates RIPK1 and RIPK3 by proteolytic cleavage and the proapoptotic caspase activation is initiated. ${ }^{12}$ Mechanistic data indicate that CYLD is essential for necrosis and serve as a target for proteolysis by caspase- $8 .{ }^{17}$ When caspase- 8 is inactivated or absent, RIPK1 and RIPK3 are not cleaved and become phosphorylated. ${ }^{1}$ They then form a necrosome ${ }^{18}$ and the cell undergoes necroptosis. ${ }^{12}$ RIPK1 then recruits RIPK3 through RIP (RHIM) domain mediatedinteractions. This RIPK1-RIPK3 interaction promotes the recruitment and phosphorylation of mixed-lineage kinase domain-like (MLKL) protein. ${ }^{18,19}$ Phosphorylated MLKL forms tetramers and translocates onto the plasma membrane, ${ }^{4,19}$ and in turn initiates $\mathrm{Ca}^{2+}$ influx. ${ }^{19}$ In addition, RIPK3 is reported to activate a number of different downstream signals such as phosphoglycerate mutase 5 and finally dynamin-related protein (Drp1) to induce reactive oxygen species (ROS) production in the mitochondria. ${ }^{14}$ The RIPK3-multimers are stabilized by chaperones that are essential for necroptosis. ${ }^{20}$

It is currently unclear which molecular switch mechanism controls the decision of whether apoptosis or necroptosis is executed, but first reports from TAK1-deficient cells suggest a critical importance of this kinase and its co-factors. ${ }^{21}$ Lamothe et $a l^{22}$ reported that TNF- $\alpha$-induced cell death was abrogated by the inhibition of caspases and knockdown of RIPK3 in TAK1-deficient mouse embryonic fibroblasts, indicating that TAK1 is an important modulator of both apoptosis and necroptosis. Saveljeva et al. ${ }^{23}$ demonstrated that repression 
Table 1 Difference between apoptosis, necrosis and necroptosis

\begin{tabular}{|c|c|c|c|}
\hline & Apoptosis & Necrosis & Necroptosis \\
\hline Type of cell death & Controlled & Uncontrolled & Controlled \\
\hline Trigger & $\begin{array}{l}\text { Trauma, toxic stress, self-renew, aging, } \\
\text { development. }\end{array}$ & Trauma, toxic stress, infection & Trauma, toxic stress, infection \\
\hline Morphology & $\begin{array}{l}\text { Extensive membrane blebbing, } \\
\text { condensation and fragmentation of the } \\
\text { nucleus }{ }^{31}\end{array}$ & $\begin{array}{l}\text { Extensive organelle and cell swelling, } \\
\text { loss of membrane integrity, release of } \\
\text { extracellular contents }\end{array}$ & $\begin{array}{l}\text { Cytoplasmic swelling, rupture of the } \\
\text { plasma membrane and spilling of the } \\
\text { intracellular content }^{99}\end{array}$ \\
\hline Signalling pathway & Specific, intrinsic or extrinsic pathways & Unspecific & Specific, e.g TNFR1 pathway \\
\hline Executioner & Caspase, (caspase-3, $-6,-7,-8$ and -9 ) & & RIP kinase (RIPK1 and RIPK3) \\
\hline Role of mitochondria & $\begin{array}{l}\text { Release of cytochrome } c \text {, interaction } \\
\text { with } \mathrm{Bcl}-2 \text { protein family. Mitochondrial } \\
\text { dysfunction }\end{array}$ & $\begin{array}{l}\text { Mitochondrial dysfunction, collapse of } \\
\text { mitochondrial membrane potential } \\
\text { Failure of ATP production }\end{array}$ & $\begin{array}{l}\text { Mitochondrial dysfunction, Production } \\
\text { of ROS. } \\
\text { AIF release }\end{array}$ \\
\hline Complex formed & Apoptosome & & Necroptosome \\
\hline Inflammatory response & Anti- or proinflammatory response & Pro-inflammatory response & Pro-inflammatory response \\
\hline DAMP release & Yes $^{100}$ & Yes & Yes \\
\hline Inhibitor & Z-VAD fmk & & Necrostatin-1 \\
\hline Human condition & Physiological or pathological condition & Pathological condition & Pathological condition \\
\hline
\end{tabular}

of TNFR1, RIPK1 or MLKL shifted endoplasmic reticulum stress induced necroptosis to apoptosis. Necroptosis is caspase independent and is not inhibited by caspase inhibitors, such as zVAD fluoromethyl ketone. ${ }^{7}$ Necroptosis can be inhibited by Necrostatin-1 through suppression of RIPK1 activity. ${ }^{24}$ The difference between apoptosis, necrosis and necroptosis is summarized in Table 1.

RIPK1 has been shown to be involved in RIPK3/MLKLdependent necroptotic cell death. ${ }^{25,26}$ However, RIPK1 was found to drive NF- $\kappa$ B-mediated cell survival and inflammation through activating downstream of either TNFR1 or TNFR2 ${ }^{27}$ as well as caspase-8-dependent apoptotic cell death. ${ }^{26}$ Depletion of RIPK1 has been shown to lead to enhanced sensitization to TNF-induced apoptosis ${ }^{26}$ and pharmacological inhibition of RIPK1 activities is associated with suppression of necroptosis. ${ }^{28}$ Recent data clearly indicate that RIPK1 serves a critical kinase-independent scaffolding role and prevents inappropriate activation of both RIPK3-dependent necroptosis and caspase-8-dependent apoptosis. . $^{25-27,29,30}$

\section{Necroptosis and Inflammation}

Necroptosis is considered to be proinflammatory ${ }^{31}$ (Figure 2). Animal studies have revealed critical involvement for necroptosis in the pathogenesis of inflammatory diseases. $^{32}$ Necroptosis is also demonstrated to lead to the release of damage-associated molecular patterns (DAMPs) $^{32}$ (Table 2). DAMPs in the extracellular milieu trigger activation of the immune system and initiate inflammation. High-mobility group protein B1 (HMGB-1) is a typical DAMP molecule that initiates inflammation through toll-like receptors TLR-2 and TLR-4. ${ }^{33}$ Lau et al. ${ }^{9}$ demonstrated that RIPK1/RIPK3-mediated necroptosis regulates $\mathrm{HMGB}-1$ release and $\mathrm{HMGB}-1$ was reduced in $\mathrm{RIPK}^{-1-}$ renal graft after injury. Further in-depth studies need to be carried out to identify DAMPs specific for necroptosis, which would provide better interpretation of the role of necroptosis in tissue inflammation and provide new therapeutic targets for inflammatory diseases. ${ }^{34}$

\section{Necroptosis in Organ Injury}

Accumulating laboratory studies demonstrate that acute or chronic organ injury can lead to necroptosis. ${ }^{35}$ To date, necroptosis has been found to be present as a result of certain disease or injury in major organs of the body (Figure 3). Understanding of necroptosis in the pathophysiology of various diseases may offer unique opportunities for clinical management of such patients.

\section{Brain}

Neonatal hypoxia-ischemia brain injury: Necroptosis has been recognized as an important mechanism of injury in neonatal hypoxia-ischemia (HI) brain injury. ${ }^{36}$ In the mouse model of neonatal $\mathrm{HI},{ }^{37}$ Necrostatin-1 blocked the interaction of RIPK1 and RIPK3 in the neurons. Cytokine gene and protein expression, such as interleukin IL-1 $\beta$, IL-6 and TNF $a$ was suppressed, and NF-kB activation was inhibited. This study showed that Necrostatin-1 could be protective against neonatal brain injury after $\mathrm{HI}$ through attenuation of necroptosis-associated neuro-inflammation.

Traumatic brain injury: Necroptosis has been shown to play a critical role in the pathogenesis of cell death during traumatic brain injury (TBI). Mice administered with Necrostatin-1 had reduced brain damage and improved motor and cognitive performance after TBI. $^{6}$ Necrostatin- 1 has been demonstrated to decrease brain neutrophil infiltration and suppress microglial activation. ${ }^{6}$ These data therefore suggest that Necrostatin-1 may offer a new therapeutic perspective for treatment of patients with TBI.

Ischemic stroke: The pathological relevance of necroptosis in an ischemic stroke setting was established in a study by Degterev et al. ${ }^{38}$ In a mouse model of transient focal cerebral ischemia, it was shown that necroptosis contributed to delayed ischemic brain injury. In addition, intracerebroventricular administration of Necrostatin-1 markedly decreased the infarct volume, indicating a therapeutic potential for stroke. 


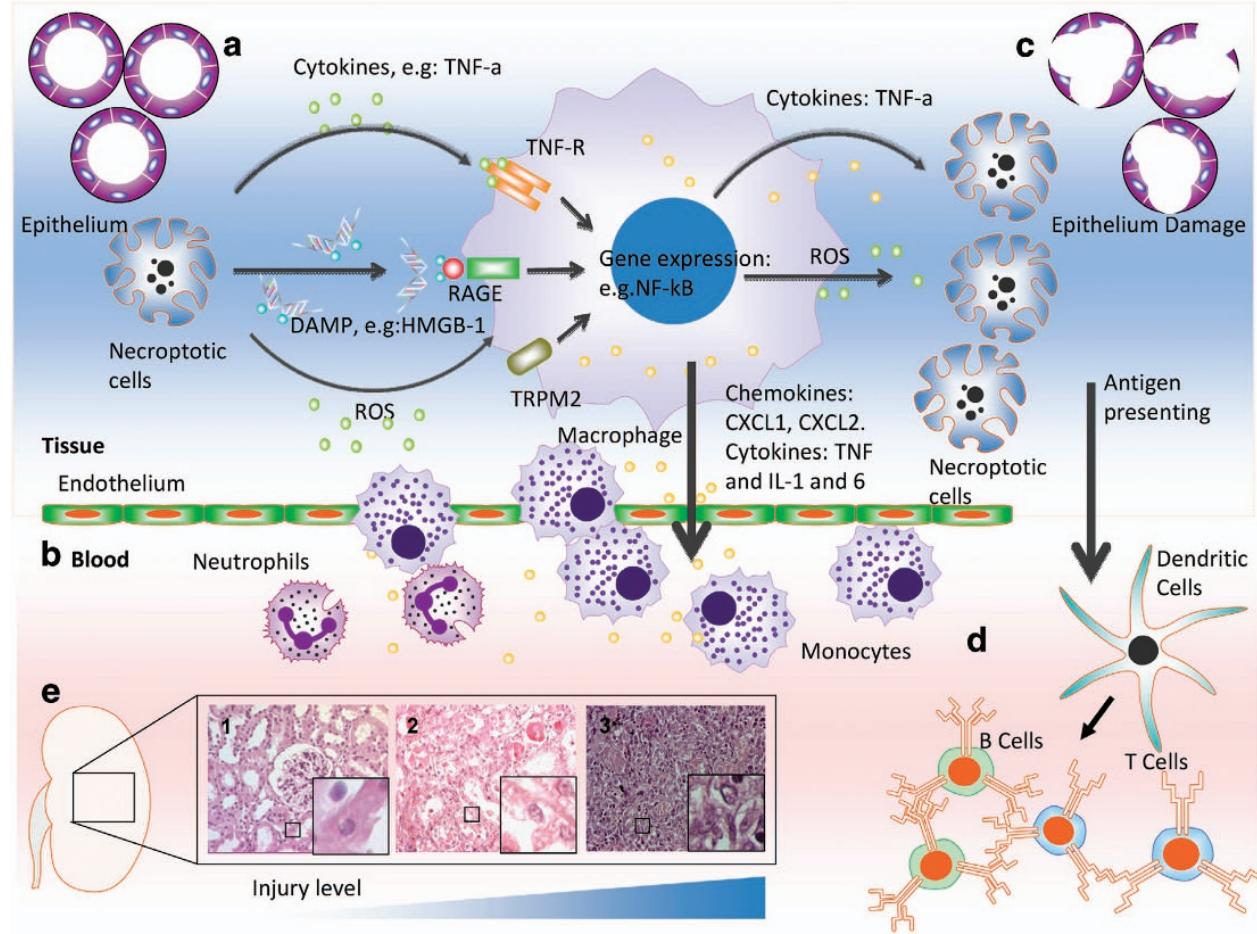

Figure 2 Necroptosis and inflammatory response. Necroptosis has been shown to commonly occur in the acute organ injury, especially in the organ transplantation. For example, during renal graft ischemia-reperfusion injury, (a) renal tubular epithelial cells undergoing necroptosis release DAMP molecules such as high-mobility group box 1 protein (HMGB-1), which is recognized by receptors, such as receptor for advanced glycation end products (RAGE) and Toll-like receptors 2, 4 and 9 (TLR-2, -4 and -9 ), reactive oxygen species (ROS) and inflammatory cytokines, such as TNF- $\alpha$, leading to immune cell activation. (b) Inflammatory cells produce and release proinflammatory chemokine (e.g. CXCL1, CXCL2) and cytokines (e.g. IL-1 and -6) and promote tissue inflammation, infiltration of monocyte and neutrophils. (c) Infiltrating monocytes produce ROS and inflammatory cytokines such as TNF- $\alpha$ enhance the necroptosis in the epithelial cells. (d) Epithelial cells undergoing necroptosis could lead to the release and presentation of donor antigens by dendritic cells and activation of the acquired immune system, such as T cells and B cells. The immune rejection is then initiated. (e) Brown-Norway rat kidney was extracted and stored in UW solution for $24 \mathrm{~h}$, and then transplanted into the Lewis recipient. Histology study demonstrated typical pathological progression possibly due to necroptosis. (1) Renal tubular cells. (2) Necrotic cells by ischemia-reperfusion injury $24 \mathrm{~h}$ after transplantation and (3) enhanced cellular infiltration during acute immune rejection 4 days after transplantation. The level of injury is gradually increased

Table 2 A list of DAMP molecules possibly associated with necrotic or/and necroptotic cells

\begin{tabular}{|c|c|}
\hline Ligand & Receptor \\
\hline $\begin{array}{l}\text { HMGB-1 } \\
\text { Histone } \\
\text { ATP } \\
\text { HSP } \\
\text { DNA } \\
\text { ECM components, e.g. fibronectin, } \\
\text { fibrinogen, hyaluronan and biglycan } \\
\text { IL-33 } \\
\text { Cyclophilin A }\end{array}$ & $\begin{array}{c}\text { RAGE, TLR-2, }-4 \text { and }-9^{101,102} \\
\text { TLR-2 and }-4^{103,104} \\
\text { P2X, P2Y } 2 Y^{105} \\
\text { CD24 } 4^{106,107} \\
\text { TLR-9 }{ }^{108} \\
\text { TLRs, CD44 } \\
\text { ST2L/IL1RAcP }{ }^{107,109} \\
\text { CD147111 }\end{array}$ \\
\hline
\end{tabular}

Hemorrhagic stroke: Although the role of necroptotic cell death after hemorrhagic stroke remains unexplored, ${ }^{39}$ the potential protective effect of Necrostatin-1 on such stroke has been investigated recently. In a mouse model of intracerebral hemorrhage, ${ }^{40}$ administration of Necrostatin-1 significantly reduced hematoma volume, neuronal cell death, reactive astrogliosis and neurovascular injury. The neurological outcomes were significantly improved after Necrostatin-1 treatment.
Amyotrophic lateral sclerosis: A study by Re et al. ${ }^{41}$ found that necroptosis is the key mechanism of neurodegeneration in both sporadic and familial types of amyotrophic lateral sclerosis (ALS). The sporadic and familial ALS astrocytes caused neuronal death by necroptosis in a RIPK1-dependent manner. Necrostatin-1 abrogated the mouse motor neuron loss in ALS.

Neurodegenerative disease: Necroptosis has been implicated in mediating neuronal excitotoxicity, which is associated with chronic neurodegeneration such as in Alzheimer's and Parkinson's diseases. ${ }^{24}$ Treatment with Necrostatin-1 protects against glutamate-induced oxytosis in hippocampal HT-22 cells. ${ }^{42}$ Furthermore, NMDA-induced excitotoxicity has been shown to be lowered in the rat cortical neurons through using Necrostatin-1.43 The molecule $24(S)$-hydroxycholesterol $(24 S-\mathrm{OHC})$ was found to induce neuronal cell death via necroptosis in a neuroblastoma cell line. ${ }^{44} 24 \mathrm{~S}-\mathrm{OHC}$ is usually found as a cholesterol eliminator in brains, with increased levels in those patients with Alzheimer's disease. ${ }^{45}$ Treatment of cells with Necrostatin-1 significantly suppressed cell death induced by $24 \mathrm{~S}-\mathrm{OHC}$. This indicated that high levels of $24 \mathrm{~S}-\mathrm{OHC}$ might 


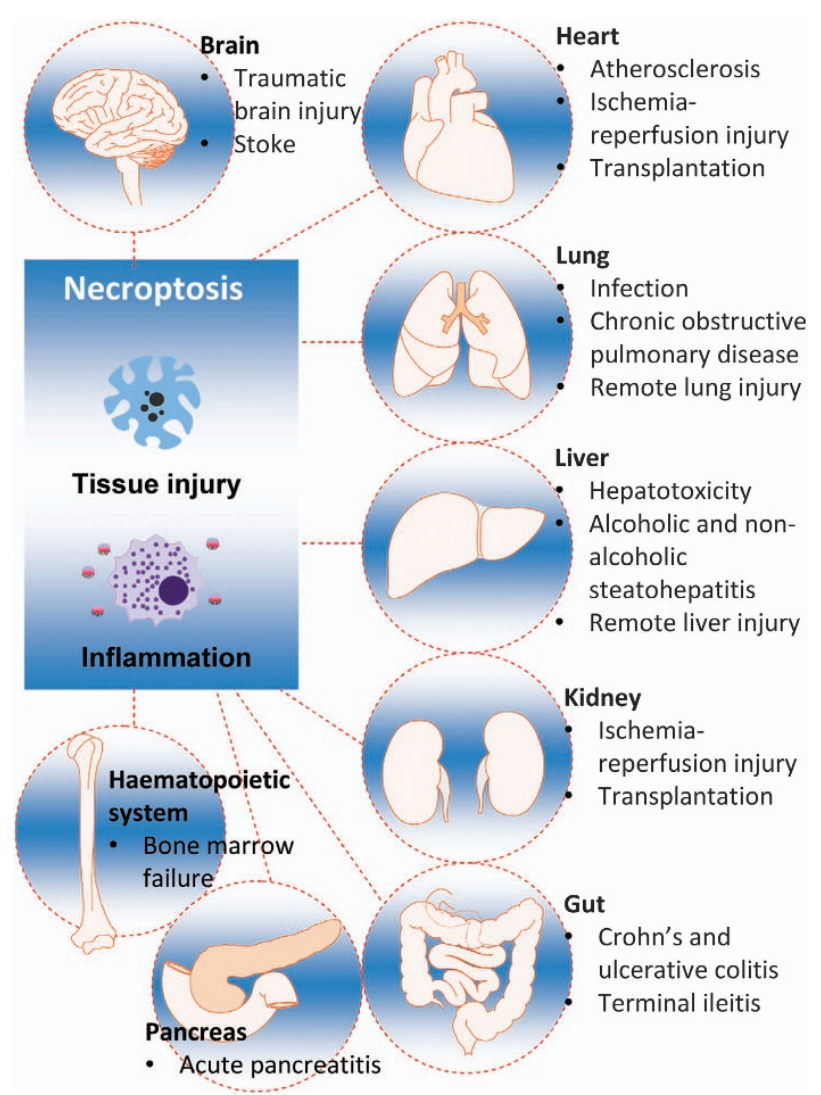

Figure 3 Necroptosis and organ injury. Necroptosis has been identified in various organs, including heart, lung, liver, kidney, gastrointestinal tract and central nervous system

lead to necroptosis of neurons and contribute to the development of neurodegenerative diseases. ${ }^{46,47}$

\section{Lung}

Lung infection: The clAP may play a role in necroptosis within the lung during pulmonary infection. ${ }^{48} \mathrm{~A}$ study of necroptosis of macrophages demonstrated that with deficient clAP-1, the mice had a greater Chlamydophila pneumoniae viral load, as well as a reduced number of macrophages. ${ }^{48}$ A deficiency in clAP-1 would increase the risk of necroptosis due to increased formation of necrosomes. Flu infections caused necroptosis in the lung and bronchiole epithelial tissue, ${ }^{49}$ mediated by RIPK1 and RIPK3, and inhibiting either or both of these proteins in mice has shown to be effective against lung infection. ${ }^{48}$ Recently, the role of necroptosis in listeria infection has been pointed out in detail. ${ }^{50}$

Remote lung injury: Several reports have independently demonstrated that necroptotis is involved in remote lung injury. A recent study by Zang et al. ${ }^{51}$ examined rat lungs that were affected by acute kidney injury (AKI), and found that the lung cells with remote injury were undergoing both apoptosis and necroptosis. Furthermore, necroptosis was reported to be involved in remote lung injury after kidney graft IRI. ${ }^{52}$ In a rat renal allogeneic transplantation model, the expression of RIPK1 was enhanced in lung alveolar epithelial cells due to renal graft IRI, possibly due to enhanced local and systemic
TNF- $a{ }^{52}$ Blocking necroptosis through Necrostatin-1 conferred protection against remote lung injury after receiving ischemic renal allografts. ${ }^{52}$

Chronic obstructive pulmonary disease: Necroptosis was described to be involved in chronic obstructive pulmonary disease. ${ }^{53}$ In a study conducted by Mizumura et al., ${ }^{53}$ cigarette smoke induced mitochondrial dysfunction in epithelial cells, and lung epithelial cells displayed increased expression of RIPK3. These findings implicated that necroptosis occurs in lung emphysematous changes in response to cigarette smoke exposure. The role of mitochondria in necroptosis has been discussed in more detail by Tait et al., ${ }^{54}$ and they demonstrated that necroptosis is executed independently of mitochondrial permeability transition.

Transfusion-induced lung injury: Red blood cell transfusion had been shown to promote lung inflammation and induced necroptosis of lung endothelial cells. ${ }^{55}$ Necroptosis and the subsequent release of inflammatory mediators is a novel mechanism of injury following transfusion that may account for the increased risk of acute respiratory distress syndrome in such patients. ${ }^{55}$

\section{Kidney}

Cisplatin-induced kidney injury: Necroptosis may be associated with the cisplatin toxicity-associated cell death ${ }^{56}$ and Necrostatin-1 has been shown to confer protection in cisplatin-treated human proximal tubular cells. ${ }^{57}$ In the mouse model of cisplatin-induced $\mathrm{AKI}$, the deterioration of renal morphology was attenuated by Necrostatin-1. ${ }^{20}$ However, there are possible explanations, which include nonnecroptotic functions of RIPK3 and off-target effects of Necrostatin-1 that might explain these findings which are not ruled out in detail. Renal tubular cells as such, when depleted from caspase-8 or FADD, are not sensitive to necroptosis in the cisplatin model. ${ }^{58}$

Renal ischemia-reperfusion injury: Recent work has further implicated the relevance of necroptosis in AKI, especially renal IRI. ${ }^{59}$ It has been demonstrated that Necrostatin-1 protects from renal IRI, a finding that suggests that RIPK1dependent necroptosis is present and has functional relevance in the pathophysiological course of ischemic kidney injury. ${ }^{28}$ Importantly, this study indicated the absence of an apoptotic contribution to deterioration of acute ischemic kidney failure. To rule out potential off-target effects of Necrostatin-1 and non-necroptotic functions of RIPK3, the potential inhibition of RIPK1-mediated necroptosis by Necrostatin-1s, a stable and highly RIPK1 kinase specific compound, remains to be investigated. Preliminary studies do not indicate a protective effect of Necrostatin-1s in this very same model. The investigation of RIPK1-kd (kinase dead) knock-in mice is currently expected to clarify this issue.

Renal transplantation: RIPK3-mediated necroptosis was demonstrated to be present in renal transplantation and has a major impact on kidney transplant survival. ${ }^{9}$ TNF- $a$ is expressed by infiltrating cells as well as kidney parenchymal cells during $\mathrm{AKI}$, which enhanced RIPK3 expression. 
Enhanced survival was observed in RIPK3 ${ }^{-/-}$kidney graft recipients. Studies to investigate Necrostatin-1s and Necrostatin-1 in a transplant setting are urgently awaited, but are delayed due to the short half-life of these small molecules. Importantly, for the transplant situation in particular, the side effects upon immunosuppression, especially viral control, should be carefully looked at.

\section{Heart}

Cardiac ischemia and infarction: It was reported ${ }^{60}$ that necrostatins inhibited myocardial cell death and reduced infarct size in the isolated perfused heart. In a study performed on guinea pig hearts, Koshinuma et al. ${ }^{61}$ looked at the effect of inhibition of necroptotic and apoptotic cell death on protection against ischemia injury. The combined treatment of necroptosis inhibitor Necrostatin-1 and apoptosis inhibitor zVAD led to reduced infarct size and a greater involvement of the RIPK1-mediated necroptosis pathway was demonstrated. ${ }^{61}$ In addition, RIPK3-deficient mice were strongly protected in a model of myocardial infarction. ${ }^{5}$ In a mouse model of cardiac IRI, ${ }^{62}$ Necrostatin-1 administration reduced infarct size, inhibited RIPK1/RIPK3 phosphorylation, and significantly reduced cell death. Therefore, Necrostatin-1 as a compound and RIPK3 as a therapeutic target currently attract tremendous interest in this pathway from pharmaceutical companies.

Cardiac transplantation: RIPK1 and RIPK3 were reported to contribute to cardiac allograft survival through necroptotic death. ${ }^{8}$ Necroptotic cell death and release of the danger molecule HMGB-1 were suppressed by Necrostatin-1 and by genetic deletion of RIPK3. RIPK3 deficiency in heart allografts led to less severe damage in the endothelium and myocytes, and prolonged graft survival after transplantation.

Atherosclerosis: RIPK3-dependent necroptosis in mouse models of atherosclerosis has been intensively investigated. ${ }^{63}$ It has been shown that RIPK3 has limited involvement in the early development of atherosclerosis, but has a promoting effect on advanced atherosclerosis. RIPK3 deficiency reduced inflammation and macrophage infiltration in advanced atherosclerotic lesions.

\section{Gastrointestinal tract}

Crohn's and ulcerative colitis: RIPK1 was reported to regulate homeostasis and suppress inflammation in barrier tissues by inhibiting epithelial cell apoptosis and necroptosis. ${ }^{64}$ A study into children with inflammatory bowel disease showed that necroptosis might contribute to its progression by heightening intestinal inflammation. ${ }^{65}$ The study, by Pierdomenico et al., found a statistically significant result in children with two main bowel diseases - namely Crohn's and ulcerative colitis. RIPK3 levels increased while caspase-8 decreased, which was a strong indicator for the presence of necroptosis. It is currently very suggestive to think of necroptosis as a cause of chronic inflammation in the gut, which might be dependent of RIPK3 and MLKL, potentially explaining the outstanding therapeutic success of infliximab, a drug that directly interferes with TNF- $a^{66,67}$
Terminal ileitis: Gunther et al. ${ }^{68}$ demonstrate necroptosis in the terminal ileum of patients with Crohn's disease and suggest that regulating necroptosis in the intestinal epithelium is critical for the maintenance of intestinal immune homeostasis. Deletion of caspase-8 from intestinal epithelial cells led to spontaneous necroptosis, causing a Crohn's-like phenotype in mice. ${ }^{68}$ Paneth cells appear to be critically involved in this process. Mice with a conditional deletion of caspase-8 in the intestinal epithelium treated with Necrostatin-1 had a much higher survival rate than those that did not receive the treatment.

\section{Liver}

Alcoholic steatohepatitis: The exact role of necroptosis in alcoholic steatohepatitis remains unclear. Roychowdhury et al. ${ }^{69}$ reported that ethanol feeding activates both apoptotic as well as non-apoptotic cell death pathways. Ethanol induced RIPK3 expression that was independent of presence or absence of caspase inhibitor. Chronic ethanol-fed mice showed increased RIPK3 expression. Moreover, the liver biopsies of alcoholic liver disease patients also showed increased RIPK3 expression, which indicates the execution of necroptosis in human hepatic pathologies. ${ }^{69}$

Non-alcoholic steatohepatitis: Gautheron et al. ${ }^{70}$ used the methionine- and choline-deficient diet-induced model of steatohepatitis as a model of non-alcoholic steatohepatitis. RIPK3 mediates liver injury, inflammation, induction of hepatic progenitor cells/activated cholangiocytes and liver fibrosis. ${ }^{70}$ RIPK3 thus represents a promising target for future therapeutic strategies in patients with chronic metabolic liver disease. It has been suggested that MLKL increases mitochondrial ROS production and contributes to necroptosis during hepatic injury. ${ }^{71}$

Hepatotoxicity: The role of Necrostatin-1 in protecting liver cell damage was recently investigated in the model of acetaminophen (APAP) induced hepatotoxicity. ${ }^{72,73}$ APAP induced the phosphorylation of RIPK1 and hence necrosome formation, and Necrostatin-1 was effective in blocking necrosome formation during APAP-induced hepatotoxicity via inhibition of RIPK1. ${ }^{72}$

Liver infection: Recent studies highlight the critical role of necroptotsis in organ infection. Infection by Listeria monocytogenes induced the early necroptotic death of Kupffer cells, which caused monocyte recruitment and an antibacterial type 1 inflammatory response. ${ }^{50}$ Kupffer cell necroptosis triggered hepatocytes to release the alarmin interleukin-33 (IL-33) and enhanced basophil IL-4 production. ${ }^{74}$ Chronic hepatitis $\mathrm{C}$ virus ( $\mathrm{HCV}$ ) infection results in progressive liver fibrosis leading to cirrhosis and liver cancer. HCV promoted cell death in primary and immortalized hepatocytes, and this was inhibited by Necrostatin-1. ${ }^{75}$ These findings indicate that $\mathrm{HCV}$-induced cell death occurs through necroptosis, and provides new insights into the mechanisms of HCV-induced liver injury. ${ }^{75}$

Remote liver injury: Necroptosis was shown to be present in remote hepatic injury associated with ischemic acute kidney 
injury (AKI). ${ }^{76}$ TNFR and RIPK3 showed significantly high expression levels in immunoblot analyses, and positive hepatocytes of RIPK3 immunohistochemical staining were also evident in livers of rats with ischemic AKI.

\section{Pancreas}

Acute pancreatitis: RIPK3 deficiency was published by two initial reports in which the role of RIPK3 was highlighted ${ }^{77,78}$ for partial protection from cerulein-induced pancreatitis (CIP), suggesting that necrotizing pancreatitis may be attenuated by pharmacological interference of this pathway. ${ }^{78,79}$ However, other groups, who intended to reproduce this result, failed to do so and in fact observed stronger organ damage in the presence of Necrostatin-1. ${ }^{79}$ Recently, the same group also described that RIPK3-deficient mice are not protected from CIP. $^{58}$ However, MLKL deficiency in a newly generated knockout mice was again shown to be responsible for the protection in the CIP model. ${ }^{80}$ In this regard, investigation of positivity for pMLKL in human pancreatitis sections would be very helpful to clarify the issue.

\section{Hematopoietic system}

Bone marrow failure: A study by Roderick et al. ${ }^{30}$ revealed that hematopoietic RIPK1 deficiency triggered both apoptotic and necroptotic death that was partially prevented by RIPK3 deficiency, but the role of TAK1 was not investigated here. Therefore, the inhibitory function of RIPK1 on RIPK3mediated necroptosis regulated hematopoiesis and prevented inflammation in this model. Interestingly, RIPK3 ${ }^{-/-}$ bone-marrow-derived dendritic cells were highly defective in lipopolysaccharide (LPS)-induced expression of inflammatory cytokines. ${ }^{81}$ This dendritic cell -specific function of RIPK3 was critical for injury-induced inflammation and tissue repair. ${ }^{81}$ Rickard et al. ${ }^{29}$ demonstrated an essential physiological role for RIPK1 in immune homeostasis and emergency hematopoiesis. RIPK1 could inhibit RIPK3/MLKL necroptosis and RIPK3 and MLKL deficiency prevented $\mathrm{RIPK}^{-/-}$systemic inflammation. Specifically, bone marrow failure described by Roderick et al. ${ }^{30}$ and Rickard et al. ${ }^{29}$ reflects the loss of normal tissue homeostasis associated with the loss of RIPK1 protein and is different from the inappropriate activation of RIPK1 kinase activity. Similarly, the study by Moriwaki et al. ${ }^{81}$ demonstrated the kinaseindependent role of RIPK3 in inflammation, which is again different from its kinase-dependent role in necroptosis.

\section{Necroptosis as a Therapeutic Target}

RIP-1 inhibitor. The central role of RIPK1 and RIPK3 in initiating necroptosis led to the assumption that inhibiting RIP is a good strategy against necroptosis. ${ }^{82,83}$ Necrostatins in animal disease models have been proven to be very useful experimental probes. ${ }^{84}$ However, RIPK1 kinase activity is not only limited to necroptosis but is also involved in $\mathrm{ERK}^{13}$ and $\mathrm{NF}-\kappa \mathrm{B}$ activation, ${ }^{85}$ therefore the biological effect after in vivo RIP inhibitor administration should be carefully interpreted. ${ }^{86}$ The kinase domain of RIPK1 appears to be of central importance in sepsis/LPS/TNF-mediated shock models. ${ }^{25,27}$ A range of chemical or biological compounds have been proposed or investigated as potential inhibitors of RIPK1 in organ injury.

Necrostatin-1: Recently, the 5-(1H-indol-3-ylmethyl)-2-thiohydantoin 1, termed Necrostatin-1 (or Nec-1), was reported to inhibit necroptosis induced by TNF- $a{ }^{82,87}$ Necrostatin-1 has been considered an effective agent of necroptosis inhibition - possibly because the main cause of necroptosis is RIPK1 and RIPK3 forming the necrosome. However, this treatment so far has only been used in the preclinical stage, so further studies are needed for its development as a drug for clinical use. The precise function of the kinase-inhibitor Necrostatin-1 is well established that this molecule is an allosteric inhibitor of RIPK1, stabilizing a specific inactive conformation of the kinase domain. ${ }^{82,88}$ It inhibits in vitro necroptosis and the in vivo effects seen with this compound are strong, and have been reported by several groups. RIPK1/3 activation is induced by homotypic RHIM domain interactions with upstream activators, such as TRIF. ${ }^{89}$ Loss of RIPK1 leads to the new parameters of direct RIPK3 activation by the same adaptors, which is clearly detrimental to the organism. However, this also indicates that the conclusion that necroptosis is RIPK1-independent has to be considered very carefully as regulation of RIPK3 in the presence of RIPK1 and its absence is not equivalent. Instead, it is clear that Necrostain-1 lacks activity in the absence of RIPK1, indicating its specific mode of action. Rather, these data indicate that RIPK1 has an important dual role in controlling cell death: both as an attenuator of RIPK3 activation under normal circumstances and as an inducer when necroptosis is activated under pathologic conditions. Thus, activation of necroptosis in $\mathrm{RIPK} 1^{-/-}$ cells is not always a clear reflection of the lack of RIPK1 role under normal circumstances. In addition, RIPK1-kd knockin mice are viable whereas whole-body RIPK1-ko are lethal at day 10.5 in utero. $^{26}$ Conversely, unlike Necrostatin-1 derivatives such as Necrostatin-1s, Necrostain-1 is a reactive and to some extent non-specific inhibitor, ${ }^{82,90}$ which may explain some discrepancies in the activities of the two molecules.

Necrostatin-1 derivatives: The new Necrostatin-1 analog, Necrostatin-1 stable (Necrostatin-1s) (7-Cl-O-Nec-1), was found to be 41000 -fold more selective for RIPK1 than for any other kinase. ${ }^{91}$ Moreover, a small group substitution at the seventh position of the indole of Necrostatin-1 and a change from thiohydantoin to hydantoin significantly enhanced its inhibitory activity. ${ }^{82}$ Necrostatin-1s was demonstrated to be very effective in reducing brain injuries $^{6,38}$

Other RIP-1 inhibitors: Harris et al. ${ }^{92}$ discovered some inhibitors for RIPK1 from three different molecule families. One of these families, furo[2,3-d]pyrimidines, has been shown to protect rats from hypothermia induced by TNF- $a .{ }^{92}$ Weng et $a l .{ }^{93}$ demonstrated that RIPK1 inhibitor GSK'963, but not inactive enantiomer GSK'962, blocks Yersinia pestis-induced cell death and caspase-8 activity. Caspase-8 conditional KO macrophages are protected from 
Y. pestis-induced death in the presence of RIPK1 (GSK'963) or RIPK3 (GSK'872) kinase inhibitors. ${ }^{93}$

RIPK3 inhibitor. The ability of RIPK3 deficiency to prevent disease has heightened interest in the therapeutic potential of small-molecule inhibitors that target RIPK3 kinase activity. Mandal et al. ${ }^{94}$ demonstrated that three selective smallmolecule compounds (GSK'840, GSK' 843 and GSK' 872 ) to inhibit RIPK3-dependent necroptosis. These compounds interact with RIPK3 to activate caspase-8 (Casp8). RIPK3inhibiting compounds blocked TNF-induced necroptosis in a concentration-dependent manner. In addition, RIPK3 inhibitors prevent death from a broader range of stimuli than RIPK1 inhibitors. Li et al. ${ }^{95}$ reported that RIPK3 activation following the induction of necroptosis required the activity of an HSP90 and a CDC37 cochaperone complex. Chemical inhibitors of HSP90 efficiently block necroptosis by preventing RIPK3 activation.

Potential cytotoxicity of RIPK3 inhibition compounds was recently observed and revealed by Mandal et al..$^{94}$ Transmission electron microscopy confirmed apoptotic cell morphology associated with RIPK3i cytotoxicity, indicating that RIPK3 inhibition compounds could induce apoptotic cell death.

Inhibitor of downstream signalling components. The downstream signalling cascade of RIPK1 may provide a significant array of novel candidate of therapeutic targets. This area certainly warrants further research.

MLKL inhibitor: The RIP downstream effector, MLKL, has been identified as another target of antinecroptosis therapy ${ }^{96}$ A new compound named necrosulfonamide ((E)- $\mathrm{N}-(4-(\mathrm{N}-(3-$ methoxypyrazin-2-yl) sulfamoyl) phenyl)-3-(5-nitrothiophene2-yl) acrylamide), referred to as NSA, can effectively block TNF-induced necroptosis in human cells through interacting with MLKL. ${ }^{4}$ NSA could become a new drug for clinical applications in treating necroptosis related human disease.

\section{Conclusion}

Based on effects seen in RIPK3-deficient mice, and on preclinical investigation of Necrostatin-1, a pathophysiological role of necroptosis in numerous diseases may be concluded. ${ }^{97,98}$ Although the molecular mechanisms of necroptosis have not been fully explored, it is clearly possible that this process is involved in promoting organ injury. Thus, further understanding of the underlying mechanisms of necroptosis and its inhibition has important implications for organ protection and should have a significant impact on the development of therapeutic intervention of related human diseases.

\section{Conflict of Interest}

The authors declare no conflict of interest.

Acknowledgements. This work was supported by the British Medical Research Council, The Developmental Pathway Funding Scheme program (project grant G802392), BJA/RCoA Research Fellowship grant. Work in the Linkermann-lab is supported by the German Research Foundation, EXC306, Inflammation at Interfaces.
1. Vandenabeele P, Galluzzi L, Vanden Berghe T, Kroemer G. Molecular mechanisms of necroptosis: an ordered cellular explosion. Nat Rev Mol Cell Biol 2010; 11: 700-714.

2. Kanduc D, Mittelman A, Serpico R, Sinigaglia E, Sinha AA, Natale $C$ et al. Cell death: apoptosis versus necrosis (review). Int J Oncol 2002; 21: 165-170.

3. Newton K, Dugger DL, Wickliffe KE, Kapoor N, de Almagro MC, Vucic D et al. Activity of protein kinase RIPK3 determines whether cells die by necroptosis or apoptosis. Science 2014; 343: 1357-1360.

4. Sun L, Wang H, Wang Z, He S, Chen S, Liao D et al. Mixed lineage kinase domain-like protein mediates necrosis signaling downstream of RIP3 kinase. Cell 2012; 148: 213-227.

5. Luedde M, Lutz M, Carter N, Sosna J, Jacoby C, Vucur M et al. RIP3, a kinase promoting necroptotic cell death, mediates adverse remodelling after myocardial infarction. Cardiovasc Res 2014; 103: 206-216.

6. You Z, Savitz SI, Yang J, Degterev A, Yuan J, Cuny GD et al. Necrostatin-1 reduces histopathology and improves functional outcome after controlled cortical impact in mice. J Cereb Blood Flow Metab 2008; 28: 1564-1573.

7. Linkermann A, Green DR. Necroptosis. N Engl J Med 2014; 370: 455-465.

8. Pavlosky A, Lau A, Su Y, Lian D, Huang X, Yin Z et al. RIPK3-mediated necroptosis regulates cardiac allograft rejection. Am J Transplant 2014; 14: 1778-1790.

9. Lau A, Wang S, Jiang J, Haig A, Pavlosky A, Linkermann A et al. RIPK3-mediated necroptosis promotes donor kidney inflammatory injury and reduces allograft survival. $A m$ $J$ Transplant 2013; 13: 2805-2818.

10. Declercq W, Vanden Berghe T, Vandenabeele P. RIP kinases at the crossroads of cell death and survival. Cell 2009; 138: 229-232.

11. Li Q, Verma IM. NF-kappaB regulation in the immune system. Nat Rev Immunol 2002; 2 : 725-734.

12. Vanlangenakker $\mathrm{N}$, Bertrand $\mathrm{MJ}$, Bogaert $\mathrm{P}$, Vandenabeele $\mathrm{P}$, Vanden Berghe $\mathrm{T}$. TNF-induced necroptosis in L929 cells is tightly regulated by multiple TNFR1 complex I and II members. Cell Death Dis 2011; 2: e230.

13. Vanlangenakker N, Vanden Berghe T, Bogaert P, Laukens B, Zobel K, Deshayes $K$ et al. CIAP1 and TAK1 protect cells from TNF-induced necrosis by preventing RIP1/RIP3dependent reactive oxygen species production. Cell Death Differ 2011; 18: 656-665.

14. Hitomi J, Christofferson DE, Ng A, Yao J, Degterev A, Xavier RJ et al. Identification of a molecular signaling network that regulates a cellular necrotic cell death pathway. Cell 2008; 135: $1311-1323$

15. Moquin DM, McQuade T, Chan FK. CYLD deubiquitinates RIP1 in the TNFalpha-induced necrosome to facilitate kinase activation and programmed necrosis. PLoS One 2013; 8 e76841

16. de Almagro MC, Goncharov T, Newton K, Vucic D. Cellular IAP proteins and LUBAC differentially regulate necrosome-associated RIP1 ubiquitination. Cell Death Dis 2015; 6 : e1800.

17. O'Donnell MA, Perez-Jimenez E, Oberst A, Ng A, Massoumi R, Xavier $R$ et al. Caspase 8 inhibits programmed necrosis by processing CYLD. Nat Cell Biol 2011; 13: 1437-1442.

18. Li J, McQuade T, Siemer AB, Napetschnig J, Moriwaki K, Hsiao YS et al. The RIP1/RIP3 necrosome forms a functional amyloid signaling complex required for programmed necrosis. Cell 2012; 150: 339-350

19. Cai Z, Jitkaew S, Zhao J, Chiang HC, Choksi S, Liu J et al. Plasma membrane translocation of trimerized MLKL protein is required for TNF-induced necroptosis. Nat Cell Biol 2014; 16 $55-65$.

20. Linkermann A, Brasen JH, Darding M, Jin MK, Sanz AB, Heller JO et al. Two independent pathways of regulated necrosis mediate ischemia-reperfusion injury. Proc Natl Acad Sci USA 2013; 110: 12024-12029.

21. Morioka S, Broglie P, Omori E, Ikeda Y, Takaesu G, Matsumoto K et al. TAK1 kinase switches cell fate from apoptosis to necrosis following TNF stimulation. J Cell Biol 2014; 204: 607-623.

22. Lamothe B, Lai $Y$, Xie M, Schneider MD, Darnay BG. TAK1 is essential for osteoclast differentiation and is an important modulator of cell death by apoptosis and necroptosis. Mol Cell Biol 2013; 33: 582-595.

23. Saveljeva S, Mc Laughlin SL, Vandenabeele P, Samali A, Bertrand MJ. Endoplasmic reticulum stress induces ligand-independent TNFR1-mediated necroptosis in L929 cells. Cell Death Dis 2015; 6: e1587.

24. Christofferson DE, Yuan J. Necroptosis as an alternative form of programmed cell death. Curr Opin Cell Biol 2010; 22: 263-268.

25. Dillon $\mathrm{CP}$, Weinlich R, Rodriguez DA, Cripps JG, Quarato G, Gurung P et al. RIPK1 blocks early postnatal lethality mediated by caspase-8 and RIPK3. Cell 2014; 157: 1189-1202.

26. Takahashi N, Vereecke L, Bertrand MJ, Duprez L, Berger SB, Divert T et al. RIPK1 ensures intestinal homeostasis by protecting the epithelium against apoptosis. Nature 2014; 513 95-99.

27. Kaiser WJ, Daley-Bauer LP, Thapa RJ, Mandal P, Berger SB, Huang C et al. RIP1 suppresses innate immune necrotic as well as apoptotic cell death during mammalian parturition. Proc Natl Acad Sci USA 2014; 111: 7753-7758.

28. Linkermann A, Brasen JH, Himmerkus N, Liu S, Huber TB, Kunzendorf U et al. Rip1 (receptor-interacting protein kinase 1) mediates necroptosis and contributes to rena ischemia/reperfusion injury. Kidney Int 2012; 81: 751-761.

29. Rickard JA, O'Donnell JA, Evans JM, Lalaoui N, Poh AR, Rogers T et al. RIPK1 regulates RIPK3-MLKL-driven systemic inflammation and emergency hematopoiesis. Cell 2014; 157: $1175-1188$. 
30. Roderick JE, Hermance N, Zelic M, Simmons MJ, Polykratis A, Pasparakis M et al. Hematopoietic RIPK1 deficiency results in bone marrow failure caused by apoptosis and RIPK3-mediated necroptosis. Proc Natl Acad Sci USA 2014; 111: 14436-14441.

31. Davidovich P, Kearney CJ, Martin SJ. Inflammatory outcomes of apoptosis, necrosis and necroptosis. Biol Chem 2014; 395: 1163-1171.

32. Pasparakis M, Vandenabeele P. Necroptosis and its role in inflammation. Nature 2015; 517 311-320.

33. Lotze MT, Tracey KJ. High-mobility group box 1 protein (HMGB1): nuclear weapon in the immune arsenal. Nat Rev Immunol 2005; 5: 331-342.

34. Kaczmarek A, Vandenabeele P, Krysko DV. Necroptosis: the release of damageassociated molecular patterns and its physiological relevance. Immunity 2013; 38 : 209-223.

35. Linkermann A, De Zen F, Weinberg J, Kunzendorf U, Krautwald S. Programmed necrosis in acute kidney injury. Nephrol Dial Transplant 2012; 27: 3412-3419.

36. Chavez-Valdez R, Martin LJ, Northington FJ. Programmed necrosis: a prominent mechanism of cell death following neonatal brain injury. Neurol Res Int2012; 2012: 257563.

37. Northington FJ, Chavez-Valdez R, Graham EM, Razdan S, Gauda EB, Martin LJ. Necrostatin decreases oxidative damage, inflammation, and injury after neonatal $\mathrm{HI}$. J Cereb Blood Flow Metab 2011; 31: 178-189.

38. Degterev A, Huang Z, Boyce M, Li Y, Jagtap P, Mizushima N et al. Chemical inhibitor of nonapoptotic cell death with therapeutic potential for ischemic brain injury. Nat Chem Bio 2005; 1: 112-119.

39. Kooijman E, Nijboer CH, van Velthoven CT, Kavelaars A, Kesecioglu J, Heijnen CJ. The rodent endovascular puncture model of subarachnoid hemorrhage: mechanisms of brain damage and therapeutic strategies. J Neuroinflammation 2014; 11: 2.

40. King MD, Whitaker-Lea WA, Campbell JM, Alleyne Jr CH, Dhandapani KM. Necrostatin-1 reduces neurovascular injury after intracerebral hemorrhage. Int J Cell Biol 2014; 2014 495817

41. Re DB, Le Verche V, Yu C, Amoroso MW, Politi KA, Phani S et al. Necroptosis drives motor neuron death in models of both sporadic and familial ALS. Neuron 2014; 81 1001-1008.

42. Xu X, Chua CC, Kong J, Kostrzewa RM, Kumaraguru U, Hamdy RC et al. Necrostatin-1 protects against glutamate-induced glutathione depletion and caspase-independent cell death in HT-22 cells. J Neurochem 2007; 103: 2004-2014.

43. Li Y, Yang X, Ma C, Qiao J, Zhang C. Necroptosis contributes to the NMDA-induced excitotoxicity in rat's cultured cortical neurons. Neurosci Lett 2008; 447: 120-123.

44. Yamanaka K, Saito Y, Yamamori T, Urano Y, Noguchi N. 24(S)-hydroxycholesterol induces neuronal cell death through necroptosis, a form of programmed necrosis. J Biol Chem 2011; 286: 24666-24673.

45. Kolsch H, Ludwig M, Lutjohann D, Rao ML. Neurotoxicity of 24-hydroxycholesterol, an important cholesterol elimination product of the brain, may be prevented by vitamin $\mathrm{E}$ and estradiol-17beta. J Neural Transm 2001; 108: 475-488.

46. Hughes TM, Kuller LH, Lopez OL, Becker JT, Evans RW, Sutton-Tyrrell K et al. Markers of cholesterol metabolism in the brain show stronger associations with cerebrovascular disease than Alzheimer's disease. J Alzheimers Dis 2012; 30: 53-61.

47. Yamanaka K, Urano Y, Takabe W, Saito Y, Noguchi N. Induction of apoptosis and necroptosis by 24(S)-hydroxycholesterol is dependent on activity of acyl-CoA:cholestero acyltransferase 1. Cell Death Dis 2014; 5: e990.

48. McComb S, Cheung HH, Korneluk RG, Wang S, Krishnan L, Sad S. clAP1 and clAP2 limit macrophage necroptosis by inhibiting Rip1 and Rip3 activation. Cell Death Differ 2012; 19 1791-1801.

49. Rodrigue-Gervais IG, Labbe K, Dagenais M, Dupaul-Chicoine J, Champagne C, Morizot A et al. Cellular inhibitor of apoptosis protein clAP2 protects against pulmonary tissue necrosis during influenza virus infection to promote host survival. Cell Host Microbe 2014 15: $23-35$

50. Bleriot C, Dupuis T, Jouvion G, Eberl G, Disson O, Lecuit M. Liver-resident macrophage necroptosis orchestrates type 1 microbicidal inflammation and type-2-mediated tissue repair during bacterial infection. Immunity 2015; 42: 145-158.

51. Zang D, Shao Y, Li X. Ultrastructural pathology of rat lung injury induced by ischemic acute kidney injury. Ultrastruct Pathol 2013; 37: 433-439.

52. Zhao H, Ning J, Lemaire A, Koumpa FS, Sun JJ, Fung A et al. Necroptosis and parthanatos are involved in remote lung injury after receiving ischemic renal allografts in rats. Kidney Int 2014; 87: 738-748.

53. Mizumura K, Cloonan SM, Nakahira K, Bhashyam AR, Cervo M, Kitada T et al. Mitophagydependent necroptosis contributes to the pathogenesis of COPD. J Clin Invest 2014; 124: 3987-4003.

54. Tait SW, Oberst A, Quarato G, Milasta S, Haller M, Wang R et al. Widespread mitochondrial depletion via mitophagy does not compromise necroptosis. Cell Rep 2013; 5 878-885.

55. Qing DY, Conegliano D, Shashaty MG, Seo J, Reilly JP, Worthen GS et al. Red blood cells induce necroptosis of lung endothelial cells and increase susceptibility to lung inflammation. Am J Respir Crit Care Med 2014; 190: 1243-1254.

56. Xu Y, Ma H, Shao J, Wu J, Zhou L, Zhang Z et al. A Role for Tubular Necroptosis in Cisplatin-Induced AKI. J Am Soc Nephrol 2015; e-pub ahead of print 18 March 2015.

57. Tristao VR, Goncalves PF, Dalboni MA, Batista MC, Durao Mde S Jr., Monte JC Nec-1 protects against nonapoptotic cell death in cisplatin-induced kidney injury. Ren Fail 2012; 34: 373-377.
58. Linkermann A, Skouta R, Himmerkus N, Mulay SR, Dewitz C, De Zen F et al. Synchronized renal tubular cell death involves ferroptosis. Proc Natl Acad Sci USA 2014; 111: 16836-16841.

59. Linkermann A, Chen G, Dong G, Kunzendorf U, Krautwald S, Dong Z. Regulated cell death in AKI. J Am Soc Nephrol 2014; 25: 2689-2701.

60. Smith CC, Davidson SM, Lim SY, Simpkin JC, Hothersall JS, Yellon DM. Necrostatin: a potentially novel cardioprotective agent? Cardiovasc Drugs Ther 2007; 21: 227-233.

61. Koshinuma S, Miyamae M, Kaneda K, Kotani J, Figueredo VM. Combination of necroptosis and apoptosis inhibition enhances cardioprotection against myocardial ischemiareperfusion injury. J Anesth 2014; 28: 235-241.

62. Oerlemans MI, Liu J, Arslan F, den Ouden K, van Middelaar BJ, Doevendans PA et al. Inhibition of RIP1-dependent necrosis prevents adverse cardiac remodeling after myocardial ischemia-reperfusion in vivo. Basic Res Cardiol 2012; 107: 270.

63. Lin J, Li H, Yang M, Ren J, Huang Z, Han F et al. A role of RIP3-mediated macrophage necrosis in atherosclerosis development. Cell Rep 2013; 3: 200-210.

64. Dannappel M, Vlantis K, Kumari S, Polykratis A, Kim C, Wachsmuth L et al. RIPK1 maintains epithelial homeostasis by inhibiting apoptosis and necroptosis. Nature 2014; 513: 90-94.

65. Pierdomenico M, Negroni A, Stronati L, Vitali R, Prete E, Bertin J et al. Necroptosis is active in children with inflammatory bowel disease and contributes to heighten intestinal inflammation. Am J Gastroenterol 2014; 109: 279-287.

66. Homsi E, Andreazzi DD, Lopes de Faria JB, Janino P. TNF-alpha-mediated cardio-renal injury after rhabdomyolysis in rats. Am J Physiol Renal Physiol 2014; 308: F1259-F1267.

67. Hanauer SB, Feagan BG, Lichtenstein GR, Mayer LF, Schreiber S, Colombel JF et al. Maintenance infliximab for Crohn's disease: the ACCENT I randomised trial. Lancet 2002; 359: 1541-1549.

68. Gunther C, Martini E, Wittkopf N, Amann K, Weigmann B, Neumann H et al. Caspase-8 regulates TNF-alpha-induced epithelial necroptosis and terminal ileitis. Nature 2011; 477 : 335-339.

69. Roychowdhury S, Chiang DJ, Mandal P, McMullen MR, Liu X, Cohen Jl et al. Inhibition of apoptosis protects mice from ethanol-mediated acceleration of early markers of CCl4-induced fibrosis but not steatosis or inflammation. Alcohol Clin Exp Res 2012; 36: $1139-1147$.

70. Gautheron J, Vucur M, Reisinger F, Cardenas DV, Roderburg C, Koppe $C$ et al. A positive feedback loop between RIP3 and JNK controls non-alcoholic steatohepatitis. EMBO Mol Med 2014; 6: 1062-1074.

71. Luedde T, Kaplowitz N, Schwabe RF. Cell death and cell death responses in liver disease: mechanisms and clinical relevance. Gastroenterology 2014; 147: 765-783 e764.

72. Takemoto K, Hatano E, Iwaisako K, Takeiri M, Noma N, Ohmae S et al. Necrostatin-1 protects against reactive oxygen species (ROS)-induced hepatotoxicity in acetaminopheninduced acute liver failure. FEBS Open Bio 2014; 4: 777-787.

73. Brune K, Renner B, Tiegs G. Acetaminophen/paracetamol: a history of errors, failures and false decisions. Eur J Pain 2014; 19: 953-965.

74. Pecaric-Petkovic T, Didichenko SA, Kaempfer S, Spiegl N, Dahinden CA. Human basophils and eosinophils are the direct target leukocytes of the novel IL-1 family member IL-33. Blood 2009; 113: 1526-1534.

75. Lim EJ, El Khobar K, Chin R, Earnest-Silveira L, Angus PW, Bock CT et al. Hepatitis C virus-induced hepatocyte cell death and protection by inhibition of apoptosis. J Gen Virol 2014; 95(Pt 10): 2204-2215.

76. Bao C, Shao Y, Li X. Hepatocyte necroptosis induced by ischemic acute kidney injury in rats. Ultrastruct Pathol 2014; 38: 217-223.

77. He S, Wang L, Miao L, Wang T, Du F, Zhao L et al. Receptor interacting protein kinase-3 determines cellular necrotic response to TNF-alpha. Cell 2009; 137: 1100-1111.

78. Zhang DW, Shao J, Lin J, Zhang N, Lu BJ, Lin SC et al. RIP3, an energy metabolism regulator that switches TNF-induced cell death from apoptosis to necrosis. Science 2009; 325: 332-336.

79. Linkermann A, Brasen JH, De Zen F, Weinlich R, Schwendener RA, Green DR et al Dichotomy between RIP1- and RIP3-mediated necroptosis in tumor necrosis factor-alphainduced shock. Mol Med 2012; 18: 577-586.

80. Wu J, Huang Z, Ren J, Zhang Z, He P, Li Y et al. Mlkl knockout mice demonstrate the indispensable role of Mlkl in necroptosis. Cell Res 2013; 23: 994-1006.

81. Moriwaki K, Balaji S, McQuade T, Malhotra N, Kang J, Chan FK. The necroptosis adaptor RIPK3 promotes injury-induced cytokine expression and tissue repair. Immunity 2014; 41: 567-578.

82. Degterev A, Hitomi J, Germscheid M, Ch'en IL, Korkina O, Teng X et al. Identification of RIP1 kinase as a specific cellular target of necrostatins. Nat Chem Biol 2008; 4 : 313-321.

83. Zhou Z, Han V, Han J. New components of the necroptotic pathway. Protein Cell 2012; 3 : 811-817

84. Trichonas G, Murakami Y, Thanos A, Morizane Y, Kayama M, Debouck CM et al. Receptor interacting protein kinases mediate retinal detachment-induced photoreceptor necrosis and compensate for inhibition of apoptosis. Proc Natl Acad Sci USA 2010; 107: 21695-21700.

85. Bertrand MJ, Vandenabeele P. RIP1's function in NF-kappaB activation: from master actor to onlooker. Cell Death Differ 2010; 17: 379-380. 
86. Takahashi N, Duprez L, Grootjans S, Cauwels A, Nerinckx W, DuHadaway JB et al. Necrostatin-1 analogues: critical issues on the specificity, activity and in vivo use in experimental disease models. Cell Death Dis 2012; 3: e437.

87. Ofengeim D, Yuan J. Regulation of RIP1 kinase signalling at the crossroads of inflammation and cell death. Nat Rev Mol Cell Biol 2013; 14: 727-736.

88. Xie T, Peng W, Liu Y, Yan C, Maki J, Degterev A et al. Structural basis of RIP1 inhibition by necrostatins. Structure 2013; 21: 493-499.

89. Kaiser WJ, Upton JW, Mocarski ES. Receptor-interacting protein homotypic interaction motif-dependent control of NF-kappa B activation via the DNA-dependent activator of IFN regulatory factors. J Immunol 2008; 181: 6427-6434.

90. Degterev A, Maki JL, Yuan J. Activity and specificity of necrostatin-1, small-molecule inhibitor of RIP1 kinase. Cell Death Differ 2013; 20: 366.

91. Christofferson DE, Li Y, Hitomi J, Zhou W, Upperman C, Zhu H et al. A novel role for RIP1 kinase in mediating TNFalpha production. Cell Death Dis 2012; 3: e320.

92. Harris PA, Bandyopadhyay D, Berger SB, Campobasso N, Capriotti CA, Cox JA et al. Discovery of small molecule RIP1 kinase inhibitors for the treatment of pathologies associated with necroptosis. ACS Med Chem Lett 2013; 4: 1238-1243.

93. Weng D, Marty-Roix R, Ganesan S, Proulx MK, Vladimer Gl, Kaiser WJ et al. Caspase-8 and RIP kinases regulate bacteria-induced innate immune responses and cell death. Proc Natl Acad Sci USA 2014; 111: 7391-7396.

94. Mandal P, Berger SB, Pillay S, Moriwaki K, Huang C, Guo H et al. RIP3 induces apoptosis independent of pronecrotic kinase activity. Mol Cell 2014; 56: 481-495.

95. Li D, Xu T, Cao Y, Wang H, Li L, Chen S et al. A cytosolic heat shock protein 90 and cochaperone CDC37 complex is required for RIP3 activation during necroptosis. Proc Natl Acad Sci USA 2015; 112: 5017-5022

96. Murphy JM, Czabotar PE, Hildebrand JM, Lucet IS, Zhang JG, Alvarez-Diaz S et al. The pseudokinase MLKL mediates necroptosis via a molecular switch mechanism. Immunity 2013; 39: 443-453.

97. Linkermann A, Stockwell BR, Krautwald S, Anders HJ. Regulated cell death and inflammation: an auto-amplification loop causes organ failure. Nat Rev Immunol 2014; 14: 759-767.

98. Vanden Berghe T, Linkermann A, Jouan-Lanhouet S, Walczak H, Vandenabeele P. Regulated necrosis: the expanding network of non-apoptotic cell death pathways. Nat Rev Mol Cell Biol 2014; 15: 135-147.

99. Vanden Berghe T, Vanlangenakker N, Parthoens E, Deckers W, Devos M, Festjens N et al. Necroptosis, necrosis and secondary necrosis converge on similar cellular disintegration features. Cell Death Differ 2010; 17: 922-930.

100. Kearney CJ, Cullen SP, Tynan GA, Henry CM, Clancy D, Lavelle EC et al. Necroptosis suppresses inflammation via termination of TNF- or LPS-induced cytokine and chemokine production. Cell Death Differ 2015; 22: 1313-1327.

101. Zhao H, Watts HR, Chong M, Huang H, Tralau-Stewart C, Maxwell PH et al. Xenon treatment protects against cold ischemia associated delayed graft function and prolongs graft survival in rats. Am J Transplant 2013; 13: 2006-2018.
102. Asavarut $\mathrm{P}$, Zhao $\mathrm{H}, \mathrm{Gu} \mathrm{J}, \mathrm{Ma} \mathrm{D}$. The role of HMGB1 in inflammation-mediated organ injury. Acta Anaesthesiol Taiwan 2013; 51: 28-33.

103. Allam R, Scherbaum CR, Darisipudi MN, Mulay SR, Hagele H, Lichtnekert J et al. Histones from dying renal cells aggravate kidney injury via TLR2 and TLR4. J Am Soc Nephrol 2012 23: $1375-1388$.

104. Abrams ST, Zhang N, Manson J, Liu T, Dart C, Baluwa F et al. Circulating histones are mediators of trauma-associated lung injury. Am J Respir Crit Care Med 2013; 187 160-169.

105. Maitre B, Magnenat S, Heim V, Ravanat C, Evans RJ, de la Salle H et al. The P2X1 receptor is required for neutrophil extravasation during lipopolysaccharide-induced letha endotoxemia in mice. $\mathrm{J}$ Immunol 2015; 194: 739-749.

106. Thaxton JE, Liu B, Zheng P, Liu Y, Li Z. Deletion of CD24 impairs development of heat shock protein gp96-driven autoimmune disease through expansion of myeloid-derived suppressor cells. J Immunol 2014; 192: 5679-5686.

107. Zhao H, Perez JS, Lu K, George AJ, Ma D. Role of Toll-like receptor-4 in renal graft ischemia-reperfusion injury. Am J Physiol Renal Physiol 2014; 306 F801-F811.

108. Kuck JL, Obiako BO, Gorodnya OM, Pastukh VM, Kua J, Simmons JD et al. Mitochondrial DNA damage-associated molecular patterns mediate a feed-forward cycle of bacteriainduced vascular injury in perfused rat lungs. Am J Physiol Lung Cell Mol Physiol 2015; 308: L1078-L1085

109. Rosin DL, Okusa MD. Dangers within: DAMP responses to damage and cell death in kidney disease. J Am Soc Nephrol 2011; 22: 416-425.

110. Haraldsen G, Balogh J, Pollheimer J, Sponheim J, Kuchler AM. Interleukin-33 - cytokine of dual function or novel alarmin? Trends Immunol 2009; 30: 227-233.

111. Dear JW, Simpson KJ, Nicolai MP, Catterson JH, Street J, Huizinga T et al. Cyclophilin A is a damage-associated molecular pattern molecule that mediates acetaminophen-induced liver injury. J Immunol 2011; 187: 3347-3352.

112. Christofferson DE, Yuan J. Cyclophilin A release as a biomarker of necrotic cell death. Cell Death Differ 2010; 17: 1942-1943.

(i) Cell Death and Disease is an open-access journal published by Nature Publishing Group. This work is licensed under a Creative Commons Attribution 4.0 International License. The images or other third party material in this article are included in the article's Creative Commons license, unless indicated otherwise in the credit line; if the material is not included under the Creative Commons license, users will need to obtain permission from the license holder to reproduce the material. To view a copy of this license, visit http://creativecommons.org/licenses/by/4.0/ 